\title{
VIBRIO CHOLERAE NON-01 NON-0139 INFECTION IN AN IMMUNOCOMPROMISED PATIENT RETURNING FROM SPAIN, JULY 2009
}

\author{
W Rozemeijer (w.rozemeijer'vumc.nl)1, L A Korswagen², A E Voskuyl², A E Budding ${ }^{1}$ \\ 1. Department of Medical Microbiology and Infection Control, VU University Medical Center, Amsterdam, the Netherlands \\ 2. Department of Rheumatology, VU University Medical Center, Amsterdam, the Netherlands
}

\begin{abstract}
We describe a severe gastroenteritis with non-01, non-0139 Vibrio cholerae in an immunocompromised patient returning from a holiday in Spain in July 2009. Predisposing factors and possible cholera enterotoxin production could explain the unusually grave symptomatology. The patient recovered after doxycyclin treatment.

In July 2009, a Dutch man in his fifties presented to an emergency department in Amsterdam with profuse diarrhoea. He had recently been diagnosed with systemic sclerosis complicated by a renal crisis, myositis and reduced motility of the stomach and small bowel (especially the duodenum). His medication included prednisone and esomeprazole.
\end{abstract}

The patient became ill the day before presentation with severe diarrhoea (more than 30 evacuations per day), vomiting and abdominal cramps. One day before onset of symptoms he had returned from Canary Islands, Spain. He had not swum in natural water nor eaten seafood during his stay. None of his family members who had accompanied him on his holiday had symptoms of gastroenteritis. On examination he was afebrile with normal pulse and blood pressure. He was severely dehydrated having lost more than $10 \%$ of his bodyweight. Laboratory tests showed an acidosis, hypokalaemia and elevated creatinine and C-reactive protein. He was hospitalised and treated with intravenous fluids and potassium.

A faecal culture was sent to the microbiology department. Its rice water appearance guided the technician to include testing for Vibrio cholerae. A lactase-negative, oxidase-positive, Gram-negative rod was identified by the Vitek system (Biomerieux, France) as $V$. cholerae. Serotyping classified it as non-01, non-0139 serotype. Disk diffusion results showed susceptibility to cefotaxime, ciprofloxacin, trimethoprim-sulfamethoxazole and tetracycline.

When culture results became available six days later, the patient was still having diarrhoea (diminished to 10 evacuations a day) and was feeling unwell. Antibiotic treatment was started with oral doxycycline $100 \mathrm{mg}$ for three days and this led to quick recovery from his gastroenteritis. Further worsening of the systemic sclerosis prevented the patient from being discharged in the following days.

In contrast to $V$. cholerae serotype 01 and 0139 , the non-01, non-0139 V. cholerae (NCV) are not associated with cholera epidemics but with sporadic cases or small outbreaks of gastrointestinal disease $[1,2]$. Occasionally these can cause extraintestinal disease including wound infections and septicaemia $[1,2]$. Few NCV strains produce cholera enterotoxin, the toxin responsible for massive dehydrating diarrhoea. Some strains can have other virulence genes leading to less severe intestinal symptoms $[1,2]$. The presence of typical choleric rice water stools and the extent of dehydration in our patient are uncommon in NCV infection and suggest cholera enterotoxin production [3]. The predisposition of this patient may have contributed to the severity of disease. He was on immunosuppressive medication, his gastric acid production was blocked by esomeprazole and the intestinal mobility was impaired $[4,5]$.

NCVs are part of the normal bacterial ecosystem of estuaries and coastal areas and these strains seem to persist in the environment, similar to V. cholerae 01 and 0139 strains [5]. NCVs are found in salt and fresh water in both the Mediterranean and temperate parts of Europe. Warm summer months favour Vibrio growth and it is in late summer and early fall that most cases occur, either through eating contaminated seafood or by direct contact with contaminated water [6-8]. A recent study in Italy, in a population with high dietary seafood intake, showed that $3.4 \%$ of the acute diarrhoea cases admitted to hospital were caused by NCV infection [7]. Most European countries do not routinely check for the presence of NCV in clinical samples, foodstuff or the environment. Our case underlines the importance of testing for $\mathrm{V}$. cholerae in potentially exposed patients with acute diarrhoea, especially when predisposing factors like immunosuppression and acid-blocking medication are present.

References

1. Kaper JB, Morris JG, Jr., Levine MM. Cholera. Clinical microbiology reviews. 1995;8(1):48-86.

2. Sack DA, Sack RB, Nair GB, Siddique AK. Cholera. Lancet. 2004;363(9404):223-33.

3. Spira WM, Daniel RR, Ahmed QS, Huq A, Yusuf A, Sack DA. Clinical features and pathogenicity of 0 group 1 non-agglutinating Vibrio cholerae and other vibrios isolated from cases of diarrhea in Dacca, Bangladesh. In: Takeya J, Zinnaka Y, editors. Proceedings of the 14th Joint Conference US-Japan Cooperative Medical Sience Program Cholera Panel; 1978. Toho University: Tokyo; 1978. p. 137-53.

4. Nalin DR, Levine RJ, Levine MM, Hoover D, Bergquist E, McLaughlin J, et al. Cholera, non-vibrio cholera, and stomach acid. Lancet. 1978;2(8095):856-9. 
5. Tobin-D'Angelo M, Smith AR, Bulens SN, Thomas S, Hodel M, Izumiya H, et al. Severe diarrhea caused by cholera toxin-producing vibrio cholerae serogroup 075 infections acquired in the southeastern United States. Clin Infect Dis. 2008;47(8):1035-40.

6. Lukinmaa S, Mattila K, Lehtinen V, Hakkinen M, Koskela M, Siitonen A. Territorial waters of the Baltic Sea as a source of infections caused by Vibrio cholerae non-01, non-0139: report of 3 hospitalized cases. Diagnostic microbiology and infectious disease. 2006;54(1):1-6.

7. Ottaviani D, Leoni F, Rocchegiani E, Santarelli S, Masini L, Di Trani V, et al. Prevalence and virulence properties of non-01 non-0139 Vibrio cholerae strains from seafood and clinical samples collected in Italy. International journal of food microbiology. 2009;132(1):47-53.

8. Stypulkowska-Misiurewicz H, Pancer K, Roszkowiak A. Two unrelated cases of septicaemia due to Vibrio cholerae non-01, non-0139 in Poland, July and August 2006. Euro Surveill. 2006;11(48):pii=3088. Available from: http://www. eurosurveillance.org/ViewArticle. aspx?ArticleId $=3088$.

This article was published on 13 August 2009.

Citation style for this article: Rozemeijer W, Korswagen LA, Voskuyl AE, Budding AE. Vibrio cholerae non-01 non-0139 infection in an immunocompromised patient returnin from Spain, July 2009. Euro Surveill. 2009;14(32):pii=19298. Available online: http:// www.eurosurveillance.org/ViewArticle.aspx?ArticleId=19298 